\title{
Tuning radiative heat flows between interior surfaces and human occupants to improve heating and cooling efficiency
}

\author{
Jin Xu and Aaswath P. Raman* \\ Department of Materials Science and Engineering, UCLA, Los Angeles, CA 90024, USA \\ *Corresponding Author: aaswath@ucla.edu
}

\begin{abstract}
Space heating and cooling in buildings account for nearly $20 \%$ of energy use globally. In most buildings this energy is used to maintain the thermal comfort of the building's human occupants by maintaining the interior air temperature at a particular set point. However, if one could maintain the human occupant's thermal comfort while decreasing the heating or increasing the cooling set point, dramatic energy savings are possible. Here, we propose and evaluate an untapped degree of freedom in improving building efficiency: dynamically tuning the thermal emissivity of interior building surfaces at long-wave infrared wavelengths to maintain thermal comfort. We show that in cold weather conditions tuning the emissivity of interior walls, floors and ceilings to a low value $(0.1)$ can decrease the set point temperature as much as $7^{\circ} \mathrm{C}$, corresponding to an energy saving of nearly $67.7 \%$ relative to high emissivity materials $(0.9)$. Conversely, in warm weather, high emissivity interior surfaces result in a $38.5 \%$ energy savings relative to low emissivity surfaces, highlighting the need for tunability for maximal year-round efficiency. Our results reveal the remarkable energy savings potential possible by better controlling the ubiquitous flows of heat that surround us in the form of thermal radiation.
\end{abstract}

Keywords: thermal comfort, energy efficiency, heating, cooling, emissivity, radiative heat transfer, radiant systems 
Energy consumption in residential and commercial buildings contributes to $30 \%$ of total greenhouse gas emissions worldwide ${ }^{1}$. In the United States, the buildings sector accounts for $41 \%$ of primary energy consumption, of which heating and cooling alone is responsible for over $35 \%{ }^{2}$. Heating in particular poses a profound challenge for broader decarbonisation goals in temperate and cool climates ${ }^{3}$. With energy consumption for heating and cooling expected to grow dramatically worldwide in coming decades ${ }^{4}$, improving the efficiency of these systems is a key part of mitigating climate change this century. The goal of heating and cooling in buildings with human occupants is to maintain their thermal comfort ${ }^{5}$. Thermal comfort is both a quantitative and qualitative judgment that connects an individual's physiological and emotional perceptions of being in a thermally comfortable state ${ }^{5,6}$.

While thermal comfort is typically assumed to be directly linked to the air temperature set point in a conditioned space, a human occupant's perception of comfort is subject to a range of other factors. These include light intensity, material properties, metabolic heat production, heat transfer coefficients and radiative heat losses to external surfaces ${ }^{7,8}$. Human skin temperature is typically $33^{\circ} \mathrm{C}^{9,10}$ in comfortable conditions, while the average heat generation rate of a standing adult is $70 \mathrm{~W} / \mathrm{m}^{211,12}$. Previous work has examined how temperature, air velocity and humidity affect thermal comfort ${ }^{13-15}$. Given the complex array of factors that influence the perception of comfort, and the pressing need for reducing energy use for heating and cooling, it is intriguing to note that an increase in the set point temperature for cooling, or a decrease in the set point for heating, by just $4^{\circ} \mathrm{C}$ can reduce energy use by up to 45 and $35 \%$ respectively ${ }^{16}$.

In an indoor environment, where most people stay in a sedentary state, more than $50 \%$ of the heat generated by the human body is released through thermal radiation in the long-wave infrared part of the spectrum ${ }^{17,18}$. The effect of radiative heat transfer on thermal comfort has been explored ${ }^{19,20}$ but remains a comparatively untapped mechanism for efficiency gains. One approach that has attracted considerable interest in recent years is tuning the radiative properties of clothing through optical approaches, making the clothing fabric more or less transparent to thermal radiation emitted from the human wearer, depending on weather conditions ${ }^{21-28}$. While conceptually attractive, this approach poses practical challenges, as it requires the human occupants of a conditioned space to wear specialized clothing depending on weather conditions. On the other hand, a small body of work over the past two decades has identified materials 
whose emissivity can be tuned in the long-wave infrared part of the spectrum relevant to roomtemperature blackbody radiation, including by electrochromic control ${ }^{29,30}$. Most encouragingly, recent progress has yielded the first metal-free flexible IR electrochromic devices, based on PEDOT:Tosylate as both the electrochromic material and electrodes ${ }^{31-33}$, with meaningful emissivity contrast and fast switching demonstrated.

Leveraging the properties of these materials, here we propose and evaluate a new approach that seeks to make the environment surrounding the human occupants responsive to their radiative heat flows, to enable dramatically improved heating and cooling efficiency.

In cold weather conditions, lower radiative heat loss from the human occupant is desirable, as the air temperature could then be maintained at a lower temperature for the same level of thermal comfort. In these conditions it would thus be preferable to have low emissivity (high reflectivity) materials in the floor, ceiling and walls surrounding an occupant. By contrast, in summer or warm weather conditions, the heat generated by a human should be dissipated to interior surfaces, as these surfaces are typically colder than skin temperature. Thus, high emissivity (and low reflectivity) materials in the surroundings would be desirable. A previous study noted that in winter, having a low emissivity wall could reduce the heat loss of a radiator in a room with no human occupant ${ }^{34}$. However, the main purpose of space heating and cooling is to ensure the thermal comfort of the human occupants inside. We thus lack an understanding of how much energy use can be reduced by controlling the thermal emissivity of interior surfaces, while maintaining the same thermal comfort level for human occupants of a conditioned space. Moreover, as we show in this work, the desired radiative properties change dramatically from low to high emissivity depending on weather conditions and the heat load, necessitating a new approach to enable maximal heating and cooling efficiency year-round.

Here, we introduce and evaluate the concept of tunable emissivity surfaces for interior spaces in the built environment. To evaluate the possible set point change and thus energy savings, we implement computational fluid dynamics (CFD) simulations of an office environment with a human occupant. In the simulations, we assume the emissivity of the inner walls can be tuned from that of a near blackbody to a very low value. We show that in cold weather conditions a decrease in the set point of nearly $7^{\circ} \mathrm{C}$ is possible relative to conventional materials if a low- 
emissivity surface is used, with a decrease of $10^{\circ} \mathrm{C}$ possible when multiple occupants are in the conditioned space. Conversely, in hot weather conditions, we show that an increase in the set point of $4^{\circ} \mathrm{C}$ can be achieved when the emissivity of the interior surfaces increases to a high value. We extend our analysis to the building scale by using EnergyPlus ${ }^{35-37}$ to evaluate the impact of heating and cooling energy use on a typical summer and winter day in a temperate climate. We show that low-emissivity interior surface can result in up to $67.7 \%$ energy savings relative to conventional materials, when heating is needed. In warm weather conditions however low emissivity interior surfaces are no longer appropriate and would result in a $38.5 \%$ energy penalty relative to high emissivity interior surfaces. Thus, tuning the interior surface's thermal emissivity enables maximal energy efficiency throughout the year, and in response to varying heat loads and conditions.

\section{Results}

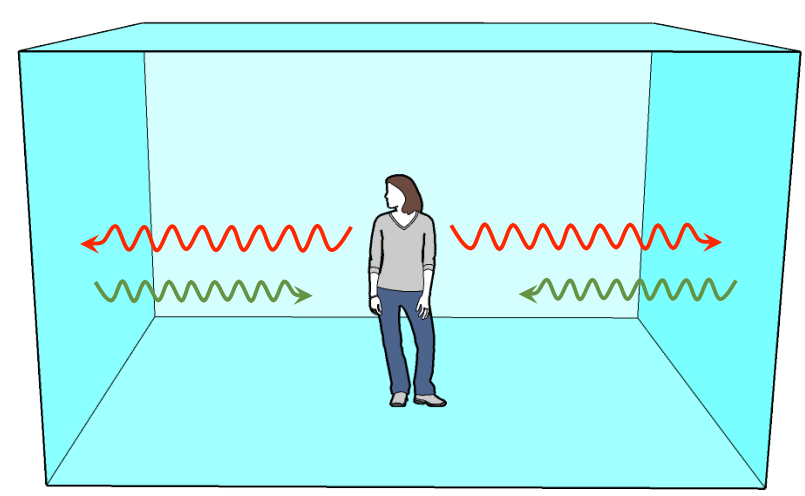

Low emissivity, high-reflectivity interior surfaces during cold-weather \& low heat-load conditions

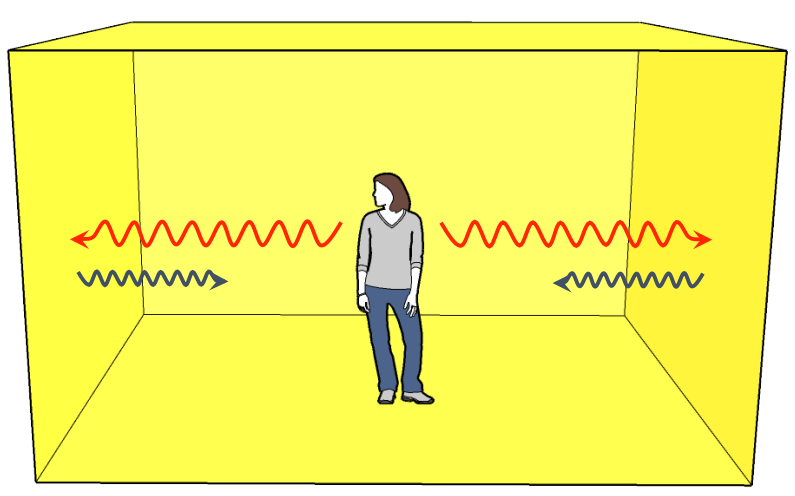

High emissivity surfaces during warm-weather and high heat-load conditions

Figure 1: Conceptual schematic of tunable emissivity surfaces: Low-emissivity, high-reflectivity interior reflects radiative heat back to the body in cold weather conditions. By contrast, high absorptivity interior walls absorb the radiative heat released from the occupant inside during warm-weather conditions

In cold weather conditions, the human body loses a significant amount of heat through both convective and radiative heat transfer to its surroundings. Since more than half this heat loss is from thermal radiation ${ }^{19}$, finding a means to reduce this radiative heat loss in interior spaces is 
potentially an effective way to keep occupants comfortable at lower air temperatures. Most building materials, such as typical paints, have high emissivity (and therefore absorptivity) in the long-wave infrared. Thus interior surfaces typically absorb the thermal radiation from the human occupant and emit back a smaller amount of thermal radiation corresponding to the lower temperature of the walls, ceilings and floors. Our goal for cold-weather conditions, schematically shown in Fig. 1, is thus to have low emissivity, high reflectivity, interior surfaces. By virtue of this property, the surfaces will send back a large fraction of the radiative heat lost by the human occupant back to them, allowing us to set the air temperature lower, thereby reducing the need for heating energy while maintaining the same level of thermal comfort (which in our study is assessed by the maintenance of constant skin temperature and fixed amount of body heat released by the human occupant).

By contrast, in summer and warm-weather conditions more generally, it is desirable to maximize the net heat rejected by the human occupant to their environment (Fig. 1). Thus, high emissivity (high absorptivity) materials in the interior of the building should be used to absorb the heat radiated by the occupant. By doing so one can maintain the same level of thermal comfort while using less cooling energy than it would be needed if the walls were low emissivity or high reflectivity. This qualitative introduction to our concept highlights a key result of our analysis: the need for tunability in the emissivity of the surfaces surrounding the human occupant, depending on weather conditions and overall heat loads.

To numerically analyze the impact of emissivity on the interior air temperature set point we developed a 3D computational model to simulate a standing person in a proto-typical conditioned space (Fig. 2)). The room, whose dimensions are $3 \mathrm{~m} \mathrm{x} 3 \mathrm{~m}$ x $3 \mathrm{~m}$, has an air inlet (shown in blue) where heating or cooling air is supplied, and multiple outlets (shown in red) to ensure adequate distribution and flow of air in the space. In winter, the heating air will come through the inlet, heat the room, and then come out the room through the outlets. In summer, the cooling air will come from the inlet, cool the room, and then exit through outlets. The human occupant is modeled as a volume heat source of $103 \mathrm{~W}^{19}$. The occupant is set to have 1.0 clo and 0.6 clo clothing insulation in the cold weather and warm weather case respectively ${ }^{38,39}$. The wall temperature is set as a constant value during the simulation to capture its large thermal mass and typical observed behavior in commercial buildings. 


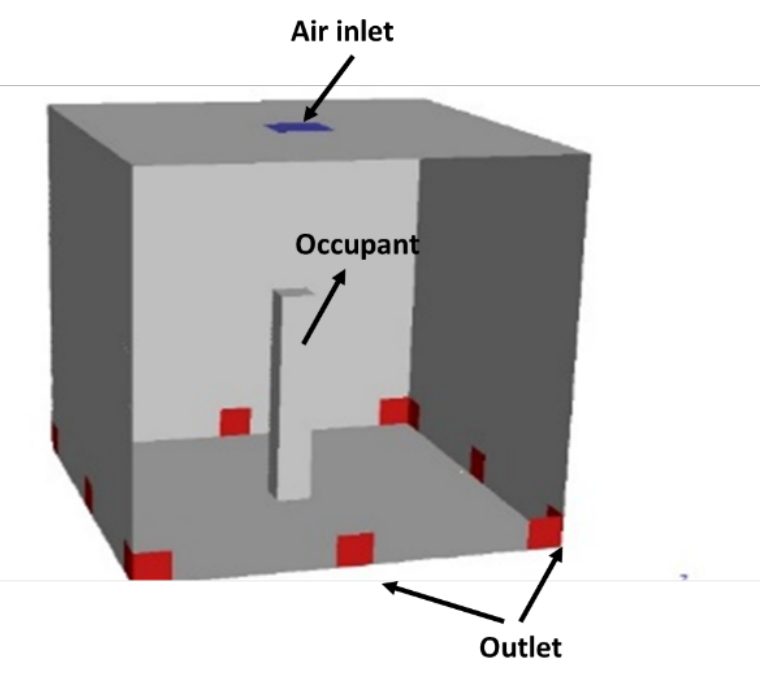

Figure 2: Computational model: 3D model built to simulate a standing person in a conditioned space, to assess the impact of tuning the thermal emissivity of the spaces that surround the human occupant.

To assess the change in set point temperature as a function of emissivity, we sought to adjust the air temperature to maintain a skin temperature of $33^{\circ} \mathrm{C}$ in response to the change in the emissivity of the interior surfaces. In doing so, we determine the change in air temperature set point possible while maintaining the human occupant's thermal comfort.

For a closed system consisted of two gray and diffuse surfaces, the radiative heat flux of the two surfaces can be analytically described as ${ }^{40}$ :

$$
Q_{1,2}=\frac{\left(E_{b 1}-E_{b 2}\right)}{\frac{1-\varepsilon_{1}}{\varepsilon_{1} A_{1}}+\frac{1}{X_{1,2} A_{1}}+\frac{1-\varepsilon_{2}}{\varepsilon_{2} A_{2}}}
$$

In the above equations, $Q_{1,2}$ is the heat flux, $A_{1}$ is the area of the hot surface and $A_{2}$ is the sum of the three cold surfaces area, $E_{\mathrm{b} 1}$ and $E_{\mathrm{b} 2}$ are the black body emission at the temperature of hot surface and cold surface respectively where $E_{\mathrm{b} 1}=\sigma T_{1}^{4}, E_{\mathrm{b} 2}=\sigma T_{2}^{4}, \sigma$ is the Stephan-Boltzmann constant, $T_{1}$ is the hot surface temperature, $T_{2}$ is the cold surface temperature, $\varepsilon_{1}$ and $\varepsilon_{2}$ are the emissivity of the hot surface and the cold surface, $X$ is the view factor.

When surface 1 is a plane or convex Eq. (2) can be simplified as ${ }^{40}$

$$
Q=\frac{A_{1}\left(E_{b_{1}}-E_{b 2}\right)}{\frac{1}{\varepsilon_{1}}+\frac{A_{1}}{A_{2}}\left(\frac{1}{\varepsilon_{2}}-1\right)}
$$


Eq. (2) can be used as a simplified way to calculate the radiative heat transfer between the occupant and their surroundings. From Eq. (2), we can further see when we decrease the emissivity of the cold surface the heat flux will be decreased as well.

\section{Cold Weather Conditions: Low Emissivity}

In the winter, or cold-weather conditions more generally, the temperature of the walls in the interior space is set to $13^{\circ} \mathrm{C}^{41}$. The heater is turned on and heating air is delivered through the inlet to the room. At the same time, the occupant inside is exchanging heat both through convection to the air and radiation to the surrounding interior surfaces. While the temperature of the occupant and the surrounding interior surfaces are difficult to change, the emissivity of the walls can be adjusted to reduce the radiative loss.

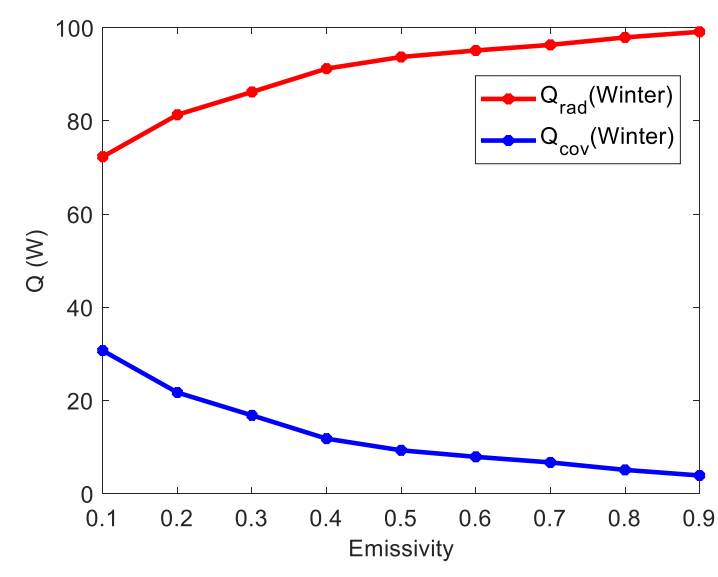

(a)

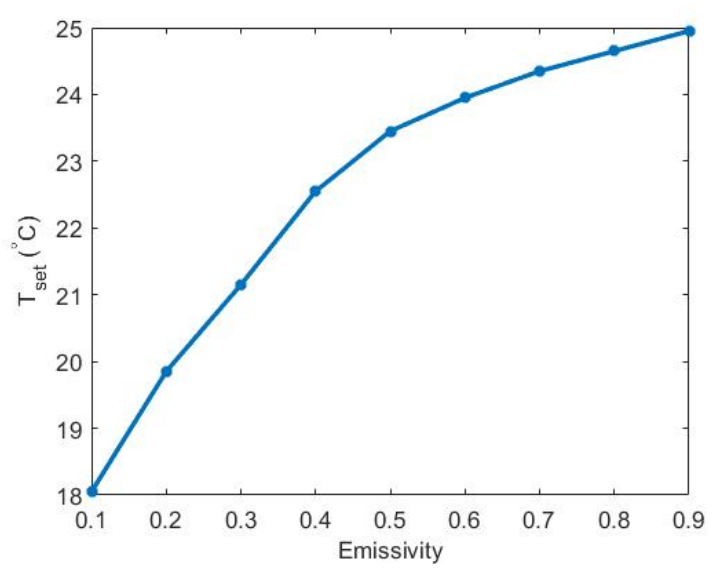

(b)

Figure 3: Cold weather, single-occupant scenario: (a) Radiative and convective heat loss of the occupant varies with the emissivity of their surroundings (b) The set point temperature for heating decreases by $7^{\circ} \mathrm{C}$ as the emissivity of the interior surfaces surrounding the human occupant go from 0.9 to 0.1 .

Using our CFD model, we first determine the radiative and convective heat exchange between the occupant and the surrounding surfaces as a function of emissivity (Fig. 3 (a)). We can see the sum of radiative heat and convective heat equal to the constant of the total heat generated by the occupant. The radiative heat loss from the occupant is reduced from $99.1 \mathrm{~W}$ to $72.3 \mathrm{~W}$ when the 
emissivity is decreased from 0.9 to 0.1 (Fig.3(a)), which matches well with the analytical model of Eq. (2); when the interior surfaces have a lower $\varepsilon_{2}$, the radiative heat loss is decreased, which allows more heat loss from the non-radiative part given the total heat loss is constant. As a result, we can decrease the set-point of the room to save heating energy, as shown in Fig. 3(b). The set point temperature decreases a remarkable amount, from $25^{\circ} \mathrm{C}$ to $18^{\circ} \mathrm{C}$, when the emissivity is tuned from 0.9 to 0.1 (Fig. 3(b)). A common trend in Fig. 3(a) and Fig. 3 b) is that the rate of change of both the radiative heat loss and set point temperature reduction is accelerated when the emissivity approaches 0 . To understand why, we can look at the analytical form of Eq.(2) which shows that as $\varepsilon_{2}$ approaches zero the impact of the denominator increases sharply, agreeing with previous observations about the impact of emissivity ${ }^{34}$.

\section{Warm Weather Conditions: High Emissivity}

In warm weather conditions, the temperature of the walls is set to $20^{\circ} \mathrm{C}^{42}$, which is still lower than human skin temperature. The air conditioner is turned on and cooling air is delivered through inlet to the room. We show in Fig. 4(a) the radiative heat flux between the occupant and the surrounding walls as a function of emissivity.

As expected, the heat released radiatively from the occupant increases significantly when the emissivity of the walls goes to near that of a blackbody (0.9). The radiative heat loss increases from $57.7 \mathrm{~W}$ for an emissivity of 0.1 to $77.2 \mathrm{~W}$ when the emissivity is 0.9 , which corresponds well with Eq. (2). Since the occupant can release more heat through radiation with a higher interior surface emissivity, which requires less heat dissipation through the non-radiative part. As a result, the cooling temperature set point can thus be increased to save energy, as shown in Fig. 4(b). The set point temperature rises nearly $4^{\circ} \mathrm{C}$, from $18^{\circ} \mathrm{C}$ to $22^{\circ} \mathrm{C}$ when the emissivity increases from 0.1 to 0.9 . 


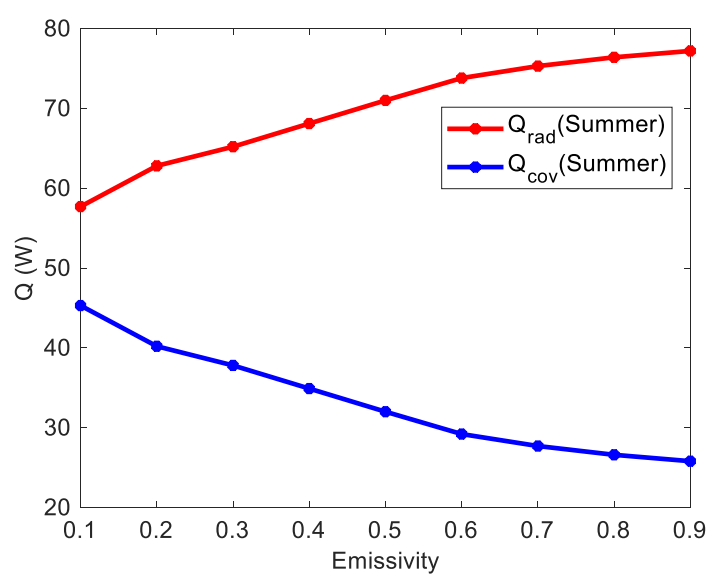

(a)

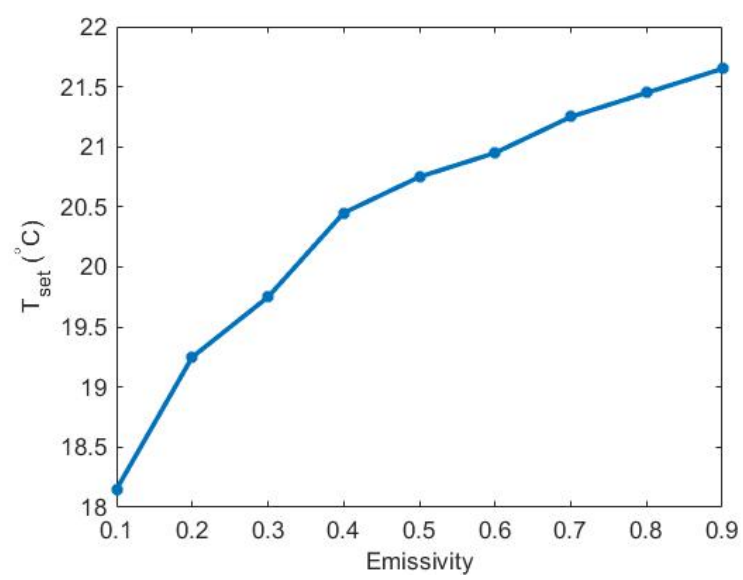

(b)

Figure 4: Warm weather, single-occupant scenario: (a) Radiative and convective heat dissipation of the occupant varies with the emissivity of their surroundings. (b) The set point temperature for cooling increases nearly $4^{\circ} \mathrm{C}$ as the emissivity of the interior surfaces surrounding the human occupant increases from 0.1 to 0.9 .

\section{Multiple Occupants}

Next, we investigated a common scenario in most buildings: the presence of more than one occupant in an interior space (Fig. 5(a)). We implement this scenario numerically in both cold weather and warm weather conditions. When there is more than one occupant in the same room, the heat source is effectively multiplied and there is not only heat transfer between occupant and surroundings, but also between occupants. In typical cases, such as a classroom or movie theater, the space between different occupants is quite narrow. If we treat the multiple occupants as one and larger heat source, the emissivity effect will be enhanced according to Eq. (2) because of the area of the hot object increases. Extending this analysis when multiple occupants are in a same room, the low emissivity walls will not only reflect their own heat back but also others' heat to them, which makes them feel warmer than single occupant case. On the other hand, in summer, if the walls reflect most of the radiative heat back, the multiple occupants will result in a significant cooling load for the air conditioner. However, if the walls can absorb most of the heat, the energy used in cooling will be substantially decreased. 


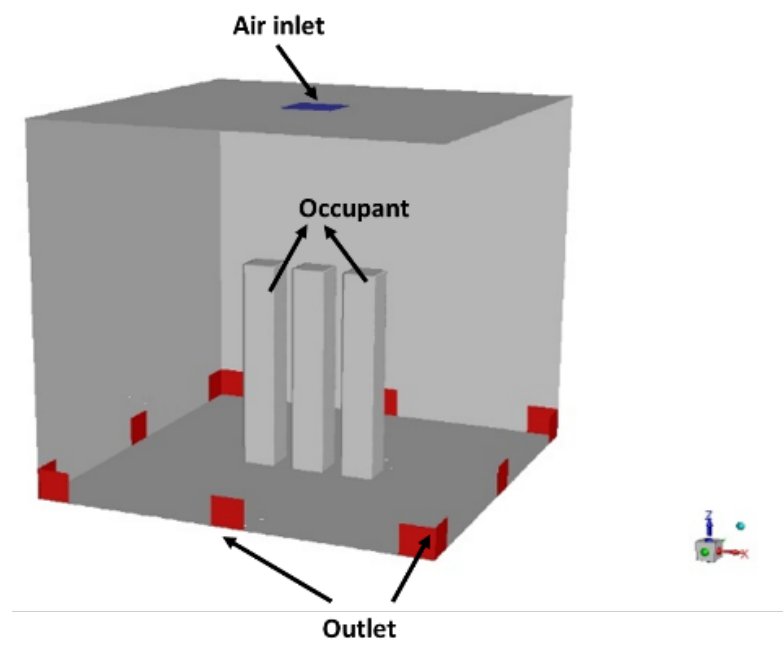

(a)

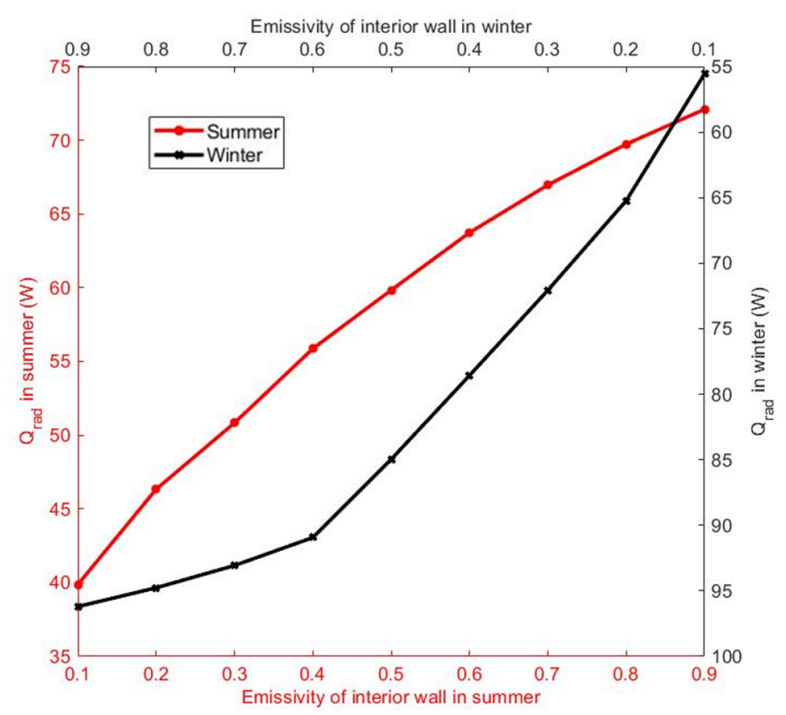

(b)

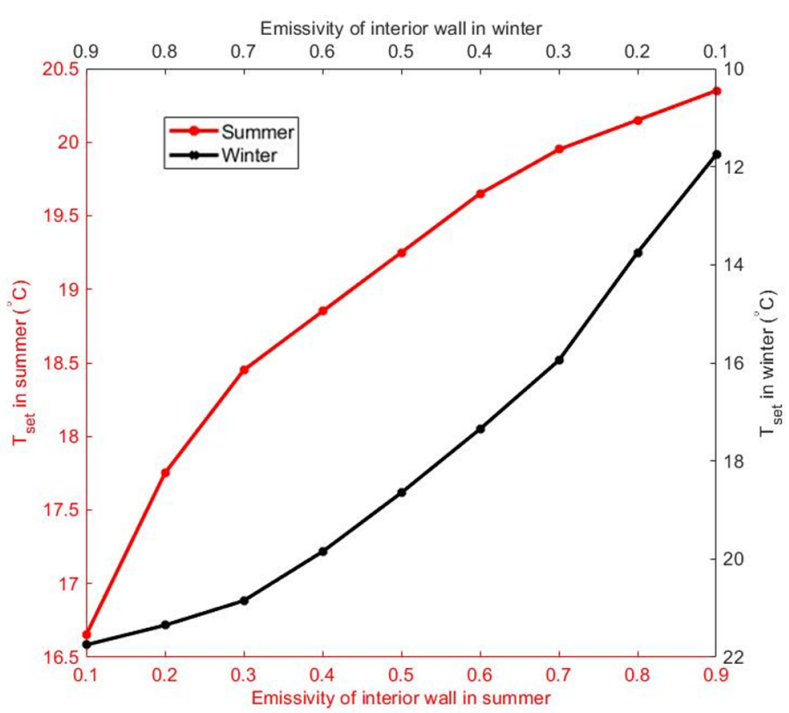

(c)

Figure 5: Multiple occupants scenario: a) Computational model for multiple occupants in a conditioned space. (b) Radiative heat loss as a function of emissivity in both cold weather (black line) and warm weather (red line) conditions. (c) The heating set point decreases from $22^{\circ} \mathrm{C}$ for an emissivity of 0.9 to $12^{\circ} \mathrm{C}$ for an emissivity of 0.1 (black line), while the cooling set point increases from $16.5^{\circ} \mathrm{C}$ to nearly $20.5^{\circ} \mathrm{C}$ as the emissivity increases from 0.1 to 0.9 . 
The radiative heat flux and set point change resulting from varying emissivity from 0.1 to 0.9 in both winter and summer are shown in Fig. 5. In the cold weather case, Fig. 5(b) shows the average radiative heat loss of each occupant decreases from $96.2 \mathrm{~W}$ to $55.5 \mathrm{~W}$ when the emissivity decreases from 0.9 to 0.1 . There is also an acceleration of change after emissivity goes below than 0.3 . This leads to a sharp set point temperature decrease of $10^{\circ} \mathrm{C}$ when the emissivity is 0.1 (shown in Fig.5(c)). Similarly, in the warm weather case, the radiative heat loss of each occupant is increased from $39.9 \mathrm{~W}$ to $72.1 \mathrm{~W}$ when the emissivity increases from 0.1 to 0.9 (Fig. $5(\mathrm{~b}))$. There is also an acceleration in the heat transfer reduction as emissivity goes below than 0.3. This leads to a sharp set point temperature decrease of up to $3.8^{\circ} \mathrm{C}$ when the emissivity is 0.1 (Fig. 5(c)), necessitating substantially more cooling. These results highlight that in dense spaces like classrooms, theaters and indoor stadiums, a significant amount of energy can be saved by implementing a tunable emissivity surface on the walls, ceilings and floors.

\section{Discussion}

To assess the building-level energy savings possible from our proposed approach, we use EnergyPlus, a widely-used building energy analysis tool ${ }^{43}$. We apply our CFD simulation results to EnergyPlus and then estimate the energy savings in a hotel-type commercial building if it uses tunable emissivity interior surfaces. We choose a small hotel reference building ${ }^{44}$ located in Ancona, Italy as our simulated environment. This hotel has a low window/ wall ratio $\left(184.2 \mathrm{~m}^{2} /\right.$

$1,695 \mathrm{~m}^{2}$ ) making it similar overall to the structure simulated in our CFD analysis ${ }^{44}$. Furthermore, Ancona has both a cold winter and a hot summer, allowing us to assess both heating and cooling energy savings. Our simulation period is a typical day in August for warm weather conditions, and December for cold weather conditions ${ }^{44}$. Fig. 6 shows the average air temperature in the August and December days modeled, corresponding to weather patterns common in a wide range of temperate climates throughout the world. 


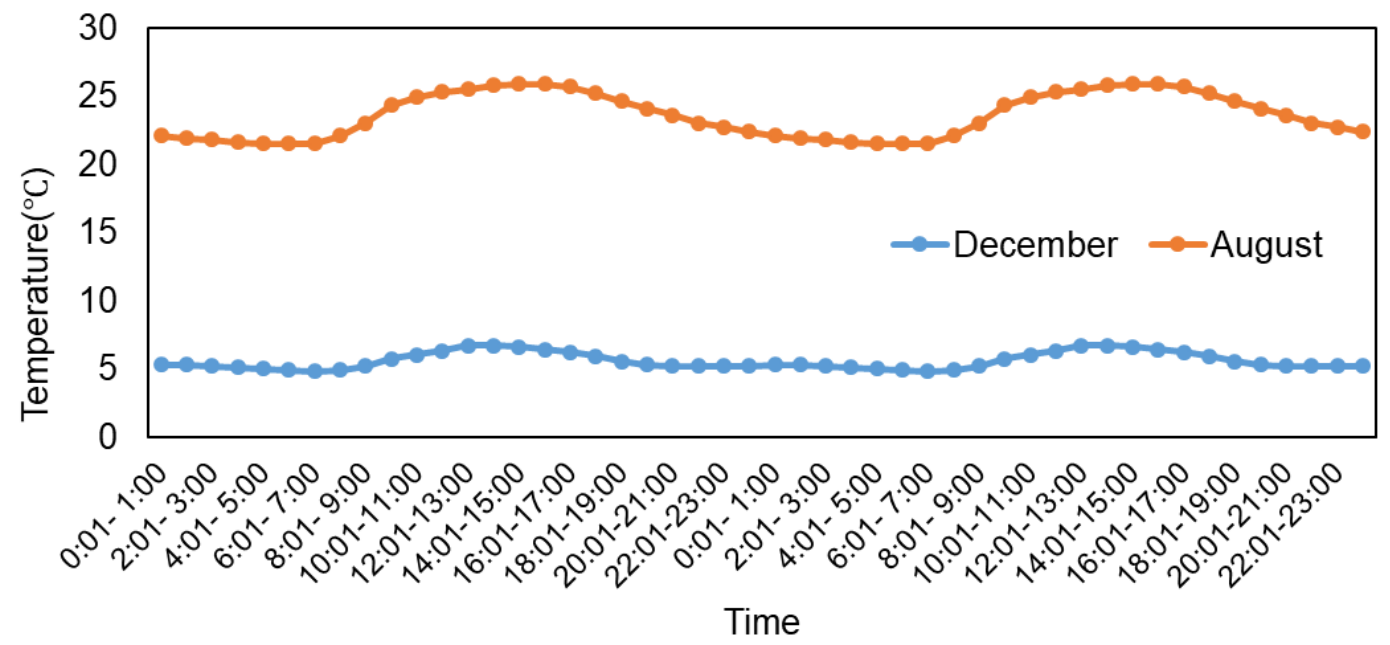

Figure 6: Weather conditions on representative summer and winter days: Measured air temperatures for a typical day in August and December in Ancona, Italy, over a full 24-hour period.

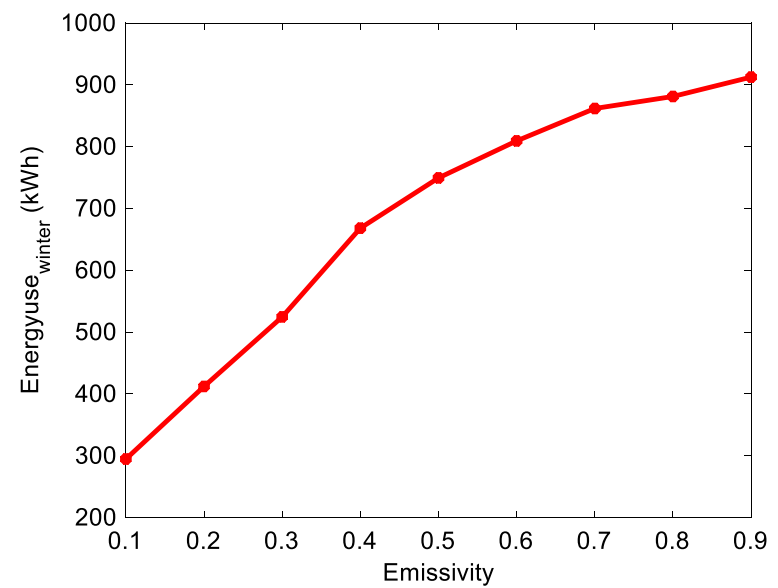

(a)

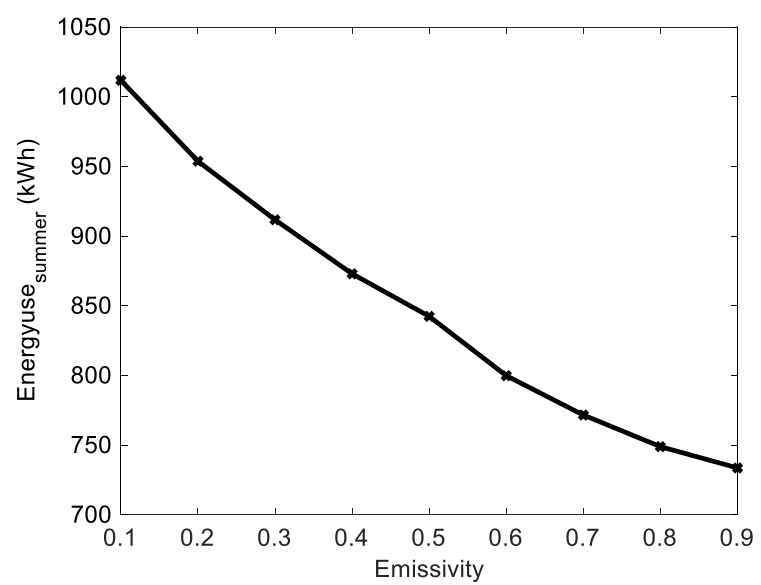

(b)

Figure 7: Energy savings as a function of interior surface emissivity: Energy use variation for (a) heating and (b) cooling in a small hotel reference building in winter and summer, modeled using EnergyPlus. 
We use the change in set point associated with a change in the interior surfaces' emissivity from 0.9 to 0.1 in winter, to model the change in heating energy use as a function of emissivity (Fig. 7). We find that the energy used for heating decreases dramatically from $910 \mathrm{kWh}$ to $300 \mathrm{kWh}$, when the emissivity decreases from 0.9 to 0.1 , corresponding to a $67.7 \%$ savings in heating energy. Conversely, during the summer day modeled, the cooling energy use in this hotel increases from $740 \mathrm{kWh}$ to $1050 \mathrm{kWh}$ when the emissivity changes from 0.9 to 0.1 , which leads to a $38.5 \%$ energy penalty if the low emissivity interior surfaces are not tuned back to high emissivity ones. While we have analyzed tunability in the context of separate days, it should be noted that tunability may also be necessary within a single day depending on variable weather conditions between day and night, and variable occupancy and heat loads.

Our results indicate that tuning the emissivity of interior surfaces can yield remarkable energy savings, particularly for heating. In recent years, a range of materials have shown the ability to tune their thermal emissivity ${ }^{29,30}$. While these preliminary works indicate that tunable emissivity is in fact possible, our results highlight the need for further investigation of tunable emissivity materials that can meet the cost and performance targets suitable for large-area application in interior spaces. In the broader context of decarbonising our built environment, the approach proposed and evaluated here represents a new strategy that can complement a range of existing strategies, including radiant heating and cooling, electrochromic windows and building integrated photovoltaics. Intriguing opportunities exist to combine the capabilities highlighted here with advances in smart building systems to develop interior spaces that dynamically respond to changing heat loads and occupants, to maximize both comfort and efficiency. More broadly, our results highlight an untapped degree of freedom for energy efficiency that lies in controlling the ubiquitous flows of heat that surround us everyday. 


\section{Methods}

\section{Computational Fluid Dynamics (CFD) Modeling}

ANSYS workbench mesh (v19.0) is used to generate the hexahedra dominated cutcell mesh for the whole domain, with a total number of 278921. The simulations are performed using ANSYS Fluent (v19.0). Steady state simulations for incompressible flows are implemented. The realizable k- $\varepsilon$ model with standard wall functions is adopted to deal with turbulence. DO (discrete ordinates) radiation model is used to calculate the radiative heat transfer between the occupants and the walls. SIMPLE algorithm is adopted to deal with the coupling of the pressure and the velocity. The discretization of the convection term in all equations is second order upwind scheme and for the diffusion term second order central scheme is used. We maintain the constant temperature of the occupants' skin and fixed heat released from them by changing the set point temperature of the room.

\section{EnergyPlus Modeling}

EnergyPlus (v7-2-0) is implemented to assess the total energy saving in the small hotel building. "HTGSETP_SCH" and "CLGSETP_SCH", which are the heating and cooling set point schedule respectively, are changed accordingly to the CFD calculation results.

\section{Acknowledgements}

J. X. acknowledges support of the China Scholarship Council (CSC). A. R. acknowledges support of the Alfred P. Sloan Foundation (Sloan Research Fellowship in Physics).

\section{References}

1. Kingma, B. \& van Marken Lichtenbelt, W. Energy consumption in buildings and female thermal demand. Nat. Clim. Chang. 5, 1054 (2015).

2. Pérez-Lombard, L., Ortiz, J. \& Pout, C. A review on buildings energy consumption information. Energy Build. 40, 394-398 (2008).

3. The heat is on. Nat. Energy 1, 16193 (2016).

4. Ürge-Vorsatz, D., Cabeza, L. F., Serrano, S., Barreneche, C. \& Petrichenko, K. Heating and cooling energy trends and drivers in buildings. Renew. Sustain. Energy Rev. 41, 85-98 
(2015).

5. FANGER, P. O. Thermal comfort. Analysis and applications in environmental engineering. (Copenhagen: Danish Technical Press., 1970).

6. Hansen, J. Literature review on thermal comfort in transient conditions. Build Env. 24, 309-316 (1990).

7. Moon, J. H., Lee, J. W., Jeong, C. H. \& Lee, S. H. Thermal comfort analysis in a passenger compartment considering the solar radiation effect. Int. J. Therm. Sci. 107, 7788 (2016).

8. Cheng, Y., Niu, J., Liu, X. \& Gao, N. Experimental and numerical investigations on stratified air distribution systems with special configuration: Thermal comfort and energy saving. Energy Build. 64, 154-161 (2013).

9. Liu, Y., Wang, L., Liu, J. \& Di, Y. A study of human skin and surface temperatures in stable and unstable thermal environments. J. Therm. Biol. 38, 440-448 (2013).

10. Liu, W., Lian, Z., Deng, Q. \& Liu, Y. Evaluation of calculation methods of mean skin temperature for use in thermal comfort study. Build. Environ. 46, 478-488 (2011).

11. American Society of Heating, R. a. A. E. (2013). Chicago Style Citation. American Society of Heating, Refrigerating and Air-Conditioning Engineers. 2013 Ashrae Handbook: Fundamentals.

12. Okamoto, T., Tamura, K., Miyamoto, N., Tanaka, S. \& Futaeda, T. Physiological activity in calm thermal indoor environments. Sci. Rep. 7, 11519 (2017).

13. Coutts, A. M., White, E. C., Tapper, N. J., Beringer, J. \& Livesley, S. J. Temperature and human thermal comfort effects of street trees across three contrasting street canyon environments. Theor. Appl. Climatol. 124, 55-68 (2016).

14. Yang, L., Yan, H. \& Lam, J. C. Thermal comfort and building energy consumption implications - A review. Appl. Energy 115, 164-173 (2014).

15. Rupp, R. F., Vásquez, N. G. \& Lamberts, R. A review of human thermal comfort in the built environment. Energy Build. 105, 178-205 (2015).

16. Hoyt, T., Lee, K. H., Zhang, H., Arens, E. \& Webster, T. Energy savings from extended air temperature setpoints and reductions in room air mixing. In International Conference on Environmental Ergonomics 2009, 608-612 (Curran Associates, Inc., 2011). in

17. Marino, C., Nucara, A. \& Pietrafesa, M. Thermal comfort in indoor environment: Effect of the solar radiation on the radiant temperature asymmetry. Sol. Energy 144, 295-309 (2017).

18. Arslanoglu, N. \& Yigit, A. Experimental and theoretical investigation of the effect of radiation heat flux on human thermal comfort. Energy Build. 113, 23-29 (2016).

19. Cai, L. et al. Warming up human body by nanoporous metallized polyethylene textile. Nat. Commun. 8, 496 (2017). 
20. Winslow, C.-E., Gagge, A. \& Herrington, L. The influence of air movement upon heat losses from the clothed human body. Am. J. Physiol. 127, 505-518 (1939).

21. Qiu, Q. et al. Highly flexible, breathable, tailorable and washable power generation fabrics for wearable electronics. Nano Energy 58, 750-758 (2019).

22. Cai, L. et al. Temperature Regulation in Colored Infrared-Transparent Polyethylene Textiles. Joule (2019).

23. Zhou, H. et al. Fabrication of flexible and superhydrophobic melamine sponge with aligned copper nanoparticle coating for self-cleaning and dual thermal management properties. Ind. Eng. Chem. Res. (2019).

24. Yue, X. et al. Ag nanoparticles coated cellulose membrane with high infrared reflection, breathability and antibacterial property for human thermal insulation. J. Colloid Interface Sci. 535, 363-370 (2019).

25. Hsu, P.-C. et al. Radiative human body cooling by nanoporous polyethylene textile. Science (80-. ). 353, 1019 LP - 1023 (2016).

26. Guo, Y. et al. Fluoroalkylsilane-Modified Textile-Based Personal Energy Management Device for Multifunctional Wearable Applications. ACS Appl. Mater. Interfaces 8, 46764683 (2016).

27. Hsu, P.-C. et al. Personal Thermal Management by Metallic Nanowire-Coated Textile. Nano Lett. 15, 365-371 (2015).

28. Tong, J. K. et al. Infrared-Transparent Visible-Opaque Fabrics for Wearable Personal Thermal Management. ACS Photonics 2, 769-778 (2015).

29. Mulford, R. B., Dwivedi, V. H., Jones, M. R. \& Iverson, B. D. Control of Net Radiative Heat Transfer With a Variable-Emissivity Accordion Tessellation. J. Heat Transfer 141, 32702 (2019).

30. Zhang, X. et al. Preparation and performances of all-solid-state variable infrared emittance devices based on amorphous and crystalline WO3 electrochromic thin films. Sol. Energy Mater. Sol. Cells 200, 109916 (2019).

31. Brooke, R. et al. Infrared electrochromic conducting polymer devices. J. Mater. Chem. C 5, 5824-5830 (2017).

32. Zhang, L. et al. Further understanding of the mechanisms of electrochromic devices with variable infrared emissivity based on polyaniline conducting polymers. J. Mater. Chem. C 7, 9878-9891 (2019).

33. Xu, J. W. et al. Electrochromic Smart Materials: Fabrication and Applications. (Royal Society of Chemistry, 2019).

34. Robinson, A. J. A thermal model for energy loss through walls behind radiators. Energy Build. 127, 370-381 (2016).

35. Kant, K., Shukla, A., Sharma, A. \& Sharma, A. Advances in simulation studies for developing energy-efficient buildings. Sustain. through energy-efficient Build. 209-233 
(2018).

36. Yu, Y., Megri, A. C. \& Jiang, S. A review of the development of airflow models used in building load calculation and energy simulation. in Building Simulation 12, 347-363 (Springer, 2019).

37. Shen, P., Dai, M., Xu, P. \& Dong, W. Building heating and cooling load under different neighbourhood forms: Assessing the effect of external convective heat transfer. Energy 173, 75-91 (2019).

38. Takada, S., Sasaki, A. \& Kimura, R. Fundamental study of ventilation in air layer in clothing considering real shape of the human body based on CFD analysis. Build. Environ. 99, 210-220 (2016).

39. Oğulata, R. T. The effect of thermal insulation of clothing on human thermal comfort. Fibres Text. East. Eur. 15, 61 (2007).

40. Lienhard, J. H. A heat transfer textbook. (Courier Corporation, 2011).

41. ANSI/ASHRAE. Thermal Environmental Conditions for Human Occupancy Standard 552013. Ashrae ASHRAE Sta, 58 (2013).

42. Joudi, A., Svedung, H., Bales, C. \& Rönnelid, M. Highly reflective coatings for interior and exterior steel cladding and the energy efficiency of buildings. Appl. Energy 88, 46554666 (2011).

43. Fumo, N., Mago, P. \& Luck, R. Methodology to estimate building energy consumption using EnergyPlus Benchmark Models. Energy and Buildings 42, 2331-2337 (2010).

44. Commercial reference buidlings. Available at:

https://www.energy.gov/eere/buildings/commercial-reference-buildings. 